\title{
Forkhead box 01 mediates defects in palmitate-induced insulin granule exocytosis by downregulation of calcium/calmodulin-dependent serine protein kinase expression in INS-1 cells
}

\author{
Yao Wang • Haiyan Lin • Nana Hao $\cdot$ Zhengqiu Zhu • \\ Dong Wang • Yuan Li • Hong Chen • Yunxia Zhu • \\ Xiao Han
}

Received: 11 September 2014 / Accepted: 24 February 2015 /Published online: 22 March 2015

(C) Springer-Verlag Berlin Heidelberg 2015

\begin{abstract}
Aims/hypothesis The transcription factor forkhead box $\mathrm{O} 1$ (FOXO1) induces pancreatic islet beta cell endoplasmic reticulum stress and is involved in fatty-acid-induced insulinsecretion defects. Cask is a downstream target gene of FOXO1. Using INS-1 cells with palmitate-induced insulinrelease defects, we investigated the relationship between FOXO1 and Cask.

Methods The expression levels and location of calcium/ calmodulin-dependent serine protein kinase (CASK) and FOXO1 were evaluated by real-time PCR, western blotting and immunofluorescence. The regulation of Cask by FOXO1 was examined using chromatin immunoprecipitation (ChIP) and luciferase assays. Potassium-stimulated insulin-secretion assays were used to verify the function of INS-1 cells and islets. Electron microscopy was used to establish the anchoring process of the insulin granules after CASK knockdown in islets.

Results Palmitic acid reduced CASK levels and increased FOXO1 levels. ChIP and luciferase assays demonstrated FOXO1 binding with the Cask promoter, which was enhanced
\end{abstract}

Electronic supplementary material The online version of this article (doi:10.1007/s00125-015-3561-4) contains peer-reviewed but unedited supplementary material, which is available to authorised users.

Y. Wang $\cdot$ N. Hao $\cdot$ Z. Zhu $\cdot$ D. Wang $\cdot$ Y. Li $\cdot$ H. Chen

Department of Endocrinology, Zhongda Hospital, Institute of

Diabetes, Southeast University, Nanjing, People's Republic of China

Y. Wang $\cdot$ H. Lin $\cdot$ Y. Zhu $\cdot$ X. Han $(\bowtie)$

Key Laboratory of Human Functional Genomics of Jiangsu

Province, Jiangsu Diabetes Center, Nanjing Medical University, 140

Hanzhong Road, Nanjing 210029, People's Republic of China

e-mail: hanxiao@njmu.edu.cn by palmitate treatment. CASK knockdown reduced insulin release in INS-1 cells and primary islets, and Cask overexpression reversed the palmitate-induced insulin reduction. CASK knockdown attenuated forskolin-enhanced insulin release, but Cask overexpression did not change the insulin-secretion suppression induced by nifedipine. In pancreatic islet beta cells, CASK knockdown reduced the anchoring of insulin vesicles to cell membranes.

Conclusions/interpretation The induction of beta cell insulinsecretion defects by fatty acids is mediated, at least in part, by FOXO1 via downregulation of Cask expression. It is characterised mainly as an obstruction of the anchoring of insulin granules to beta cell membranes.

Keywords CASK · FOXO1 - Insulin secretion · Palmitate · Pancreatic beta cells

\begin{tabular}{|c|c|}
\hline \multicolumn{2}{|c|}{ Abbreviations } \\
\hline AD-siFoxol & Adenovirus for Foxol-specific siRNA \\
\hline CASK & $\begin{array}{l}\text { Calcium/calmodulin-dependent serine } \\
\text { protein kinase }\end{array}$ \\
\hline ChIP & Chromatin immunoprecipitation \\
\hline FOXO1 & Forkhead box $\mathrm{O} 1$ \\
\hline GFP & Green fluorescent protein \\
\hline KSIS & Potassium-stimulated insulin secretion \\
\hline MAFA & $\begin{array}{l}\text { V-maf musculoaponeurotic fibrosarcoma } \\
\text { oncogene family protein A }\end{array}$ \\
\hline NCOR & Nuclear receptor co-repressor \\
\hline NEUROD & Neurogenic differentiation factor \\
\hline PKA & Protein kinase A \\
\hline PDX-1 & Pancreatic and duodenal homeobox-1 \\
\hline qRT-PCR & Quantitative RT-PCR \\
\hline si(RNA) & Small interfering (RNA) \\
\hline
\end{tabular}


SMRT Silencing mediator of retinoic acid and thyroid hormone receptor

\section{Introduction}

Glucose homeostasis requires the overall balance of cell proliferation and apoptosis or cell death of pancreatic beta cells. All types of diabetes have the common feature of islet beta cell dysfunction specifically manifested as disorders of insulin synthesis and/or secretion [1-3].

The increased global incidence of type 2 diabetes is closely related to obesity $[4,5]$. In obese individuals, the levels of plasma NEFA are significantly elevated [6]. Excessive accumulation of adipose tissue and increased size of fat cells and NEFA release leads to lipid metabolic disorder [7]. The insulin resistance of peripheral tissues such as liver, fat and muscle results in apoptosis and the dysfunction of insulin secretion of beta cells [8], but its exact molecular mechanism is still unclear.

Endoplasmic reticulum stress induced by lipotoxicity causes beta cell injury, and transcription factor forkhead box $\mathrm{O} 1$ (FOXO1) is a key regulatory factor in this process [9]. Activation of FOXO1 is necessary for fatty-acid-induced apoptosis in pancreatic beta cells, while the inhibition of FOXO1 can effectively protect islet beta cells from the toxic effects of fatty acids [10, 11]. Previously, we used palmitate-treated MIN6 cells as a model of apoptosis, and chromatin immunoprecipitation (ChIP) coupled to a DNA selection and ligation technology to identify 189 genes to which the FOXO1 protein bound [12]. The Cask gene was identified as one of the target genes of FOXO1.

Calcium/calmodulin-dependent serine protein kinase (CASK) is a member of the membrane-associated guanylate kinase (MAGUK) protein family. Members of this family are involved in both the development of the nervous system and the exocytotic function of neurotransmitters [13-15]. Cask is also highly expressed in pancreatic islets and beta cell lines [16]. As the processes of insulin secretion in islet beta cells are similar to the processes involved in the release of neurotransmitters from neurons [17], we investigated the regulation of Cask by FOXO1 in pancreatic islet beta cells. In addition, we examined whether these proteins are involved in the development of high-fat-induced beta cell dysfunction, and if they have any effect on the exocytotic action of insulin granules.

\section{Methods}

Reagents For details of reagents and suppliers, see the electronic supplementary material (ESM) Methods.
Cell culture and fatty acid administration The rat insulinoma cell line INS-1 [18] culture method is described in detail in the ESM Methods. Cultured cells were treated with drugs as described or, as a control, DMSO $<0.1 \%$ (vol./vol.). For fatty acid administration, INS-1 cells were incubated in modified 1640 medium with $0.5 \%$ (wt/vol.) BSA alone or with different concentrations of palmitate for the indicated times. Fatty acids at $0.4 \mathrm{mmol} / \mathrm{l}$ were prepared as previously described [19].

Real-time PCR Total RNA was extracted using Trizol reagent (Invitrogen, Grand Island, NY, USA). Complementary DNA synthesis was performed using $1 \mu \mathrm{g}$ total RNA and an avian myeloblastosis virus (AMV) reverse transcription system. Quantitative (q)RT-PCR was performed using the SYBR Green PCR Master Mix and LightCycler480 II Sequence Detection System (Roche, Basel, Switzerland). All data were analysed using $\beta$-actin gene expression as an internal standard. The sequences of primers are shown in ESM Table 1.

Western blot analysis INS-1 cells were lysed with ice-cold lysis buffer and complete proteinase inhibitor mixture. After protein content determination and separation with $12 \%$ (wt/ vol.) SDS-PAGE, western blotting was performed, as described previously [20], using antibodies against FOXO1 (diluted 1:1,000), pancreatic and duodenal homeobox-1 (PDX-1) (1:2,000), CASK (1:1,000), NEUROD (1:8,000), V-maf musculoaponeurotic fibrosarcoma oncogene family protein $\mathrm{A}$ (MAFA) $(1: 1,000)$ and $\alpha$-tubulin $(1: 8,000)$ in $2.5 \%$ (wt/vol.) non-fat dried milk in Tris-buffered saline with Tween-20 (TBST) buffer.

Immunocytofluorescent staining INS-1 cells were cultured as described above, and then seeded onto polylysine-coated glass cover slips with indicated drugs. Immunocytofluorescent staining was performed as described previously [20].

Plasmid construction The DNA fragment containing the rat Cask promoter region ( $-1,885 \mathrm{bp}$ to $-726 \mathrm{bp})$ was amplified by PCR from rat genomic DNA using the Pyrobest PCR kit (Takara, Otsu, Japan). The PCR products were then subcloned into the KpnI and SacI sites of the pGL3-promoter vector to construct the pGL3-basic-rat-Cask-promoter plasmid or subcloned into the XhoI and SalI sites of the $\mathrm{pE}$ green fluorescent protein (GFP)-N2 vector (Promega, Madison, WI, USA) to construct the pEGFP-N2-Cask plasmid and then the integrity of the plasmid was confirmed by sequencing. The primers are listed in ESM Table 2. The CA-Foxo1 ADA plasmid was constructed as described previously [21].

ChIP assay Preparation of chromatin from INS-1 cells and subsequent ChIP assays were done with a ChIP assay kit (Upstate Biotechnology, NY, USA) as described in the ESM Methods. The presence of the selected DNA sequence was 
assessed by PCR using primers framing the rat Cask promoter region of interest $(-1,842$ to $-1,580 \mathrm{bp}, 263 \mathrm{bp})$, which was predicted and analysed using MatInspector/MatBase provided by Genomatix to have an abundance of Foxol conserved domain TRTTTAY: forward primer 5'-CCCGAAAGAAGACA AAGTG-3' and reverse primer 5'-GAAGATTCAGCCTATT TCCC-3'.

Cell transient transfection and luciferase assay To investigate the transcriptional activity of Cask in INS-1 cells after palmitate treatment and the effect of FOXO1 on Cask gene transcription, we used pRL-SV40 as an internal control. The INS1 cells were transiently transfected with two or three plasmids using the Lipofectamine 2000 reagent: pGL3-basic-rat Cask promoter and PRL-SV40; or pGL3-basic-rat-Cask promoter together with either control pCMV5 vector plasmid or pCMV5-Foxo1 expression plasmid and PRL-SV40. The former cells were treated with palmitate for the indicated times and then prepared for luciferase determination according to the protocol of the dual-luciferase reporter assay system. The latter cells were lysed and assayed for luciferase activity $24 \mathrm{~h}$ after transfection. The control pCMV5 vector plasmid or pCMV5-Foxo1 expression plasmid were obtained from our laboratory stock: the sequences and preparation have been described in detail previously $[21,22]$.

RNA interference Specific small interfering (si)RNAs and control siRNA were designed and synthesised by RiboBio (Guangzhou, China). INS-1 cells and islets were transiently transfected with siRNA using Lipofectamine 2000 reagent (see the ESM Methods for further details). After further incubation for $48 \mathrm{~h}$, the cells were harvested for evaluation of insulin secretion and mRNA expression or protein levels, and islets were harvested for potassium-stimulated insulin secretion (KSIS) and electron microscopy. The siRNAs used in the study are described in ESM Table 3. We also used adenovirus-mediated RNA interference (RNAi) with AdsiFoxol (obtained from our laboratory stock-the sequences and preparation have been described in detail previously $[21,22])$ to knockdown FOXO1 in INS-1 cells.

KSIS assay INS- 1 cells $\left(7.0 \times 10^{4}\right.$ cells/well $)$ were cultured in 48-well plates and treated with the indicated drugs for $48 \mathrm{~h}$. After incubation for $1 \mathrm{~h}$ in glucose-free KRB buffer (see the ESM Methods for details) and drug solutions, the cells were treated for $1 \mathrm{~h}$ in KRB buffer and drug solutions with low glucose $(2.8 \mathrm{mmol} / \mathrm{l})$ and $\mathrm{KCl}(50 \mathrm{mmol} / \mathrm{l})$, which can cause closure of $\mathrm{K}^{+}{ }_{\text {ATP }}$ channels, depolarisation of the plasma membrane, increased cytoplasmic calcium concentrations through voltage-gated calcium channels, and exocytosis of insulin granules. The supernatant fractions were obtained for insulin concentration determination using RIA as described previously [23].
Islet isolation, culture and electron microscopy All animal studies were performed according to guidelines established by the Research Animal Care Committee of Nanjing Medical University. Male 8-week-old Sprague Dawley rats and $d b / d b$ mice were purchased from Nanjing Medical University Laboratory Animal Center and National Resource Center for Mutant Mice (NRCMM). Islet isolation and culturing techniques have been described previously [24]. After culture, counting and equilibration, the islets were harvested and fixed in $2.5 \%$ (vol./vol.) glutaraldehyde for $1 \mathrm{~h}$ at $4^{\circ} \mathrm{C}$, treated with $1 \%$ (wt/vol.) osmium tetroxide, dehydrated and embedded in Durcupan (Sigma-Aldrich, Stockholm, Sweden). Ultra-thin sections $(70-90 \mathrm{~nm})$ were put on $\mathrm{Cu}$ grids and contrasted with uranyl acetate and lead citrate before examination by electron microscopy (JEM 1230; JEOL, Tokyo, Japan).

Statistics Comparisons were performed using ANOVA for multiple groups or the Student's $t$ test for two groups. Data were presented as mean \pm SEM. A value of $p<0.05$ was considered statistically significant and significance is shown on the figures.

\section{Results}

Palmitate treatment enhances expression and transcriptional activity of Foxol Using qRT-PCR and western blotting, we demonstrated that treating INS-1 cells with different concentrations of palmitate for $12 \mathrm{~h}$ or with palmitate $(0.2 \mathrm{mmol} / \mathrm{l})$ for $6 \mathrm{~h}, 12 \mathrm{~h}$ or $24 \mathrm{~h}$ led to a dramatic increase in Foxol expression; the increase in mRNA was approximately 2.5- to 3.0fold with $0.4 \mathrm{mmol} / \mathrm{l}$ palmitate or incubation for $24 \mathrm{~h}$ (Fig. 1ad). To explore whether this upregulation was associated with the activation of the Foxol promoter region, we used a luciferase reporter plasmid: the Foxol promoter binding sites $6 \times$ Daf-16 family protein-binding element (DBE) that had been constructed previously [12]. The result revealed that the transcriptional activity of Foxol increases with palmitate treatment (Fig. 1e, f). Moreover, the expression of Foxol mRNA was increased by about $40 \%$ in islets from $d b / d b$ mice (Fig. 1g).

Palmitate treatment suppresses expression and transcriptional activity of Cask To evaluate the effects of palmitate on Cask expression, cells were incubated with different concentrations of palmitate for $24 \mathrm{~h}$ or with $0.2 \mathrm{mmol} / \mathrm{l}$ palmitate for $12 \mathrm{~h}$, $24 \mathrm{~h}$ or $36 \mathrm{~h}$. The expression of Cask mRNA was reduced to approximately $60 \%$ compared with the control (Fig. 2a, b), and this reduction was confirmed by western blotting (Fig. 2c, d). Similarly, the expression of Cask mRNA was reduced to about $55 \%$ in $d b / d b$ mice islets (Fig. 2i). A luciferase reporter plasmid (pGL3-basic-rat Cask promoter) was 
Fig. 1 The expression and transcriptional activity of Foxol are increased by palmitate treatment. INS- 1 cells were treated with palmitate $(0,0.2,0.4$ or $0.6 \mathrm{mmol} / \mathrm{l}$ ) for $12 \mathrm{~h}$ or for the times shown with $0.2 \mathrm{mmol} / \mathrm{l}$ palmitate. The expression levels of Foxol were analysed by realtime PCR $(\mathbf{a}, \mathbf{b})$ and western blotting $(\mathbf{c}, \mathbf{d})$. The transcriptional activity of Foxol was analysed using a luciferase assay $(\mathbf{e}, \mathbf{f})$. The expression of Foxol in $d b / d b$ mice was detected by real-time PCR (g). Values are means \pm SD and are representative of three individual experiments. ${ }^{*} p<0.05$ and ${ }^{* *} p<0.01$ vs controls
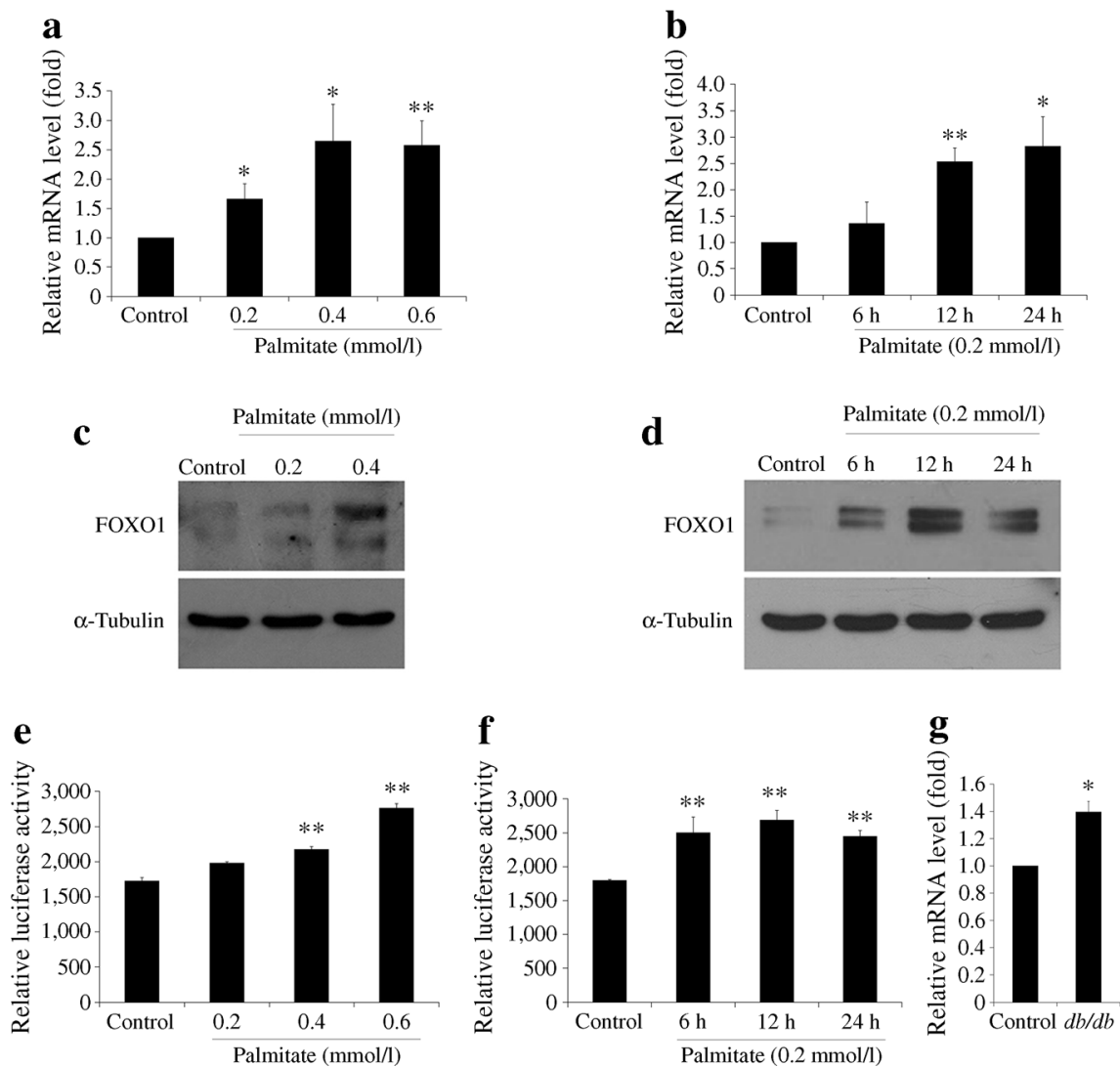

constructed that contained the Cask gene transcriptional site $(-1,885 \mathrm{bp}$ to $-726 \mathrm{bp})$. The luciferase assay revealed that the transcriptional activity of Cask decreases with palmitate treatment (Fig. 2e, f). However, palmitate treatment had no observable impact on the cellular location of CASK (Fig. $2 \mathrm{~g}, \mathrm{~h}$ ).

Negative regulation of Cask by $\mathrm{FOXO1}$ with palmitate stimulation To assess the effect of FOXO1 on Cask activity, a pair of primers was designed that demarcated a region of the Cask gene that included the Cask promoter and the FOXO1 binding sites (upstream $-1,842$ bp to $-1,580$ bp). Then ChIP was performed using FOXO1 antibody. The results show that the promoter activity of Cask was enhanced with transfection of plasmid (CA-Foxol ADA) and a slight increase of the binding of FOXO1 to this region with palmitate treatment (Fig. 3a, b).

When the PCMV5-Foxol overexpression plasmid [12] and the pGL3-basic-rat Cask promoter were co-transfected into INS-1 cells, the transcriptional activity and expression of Cask were significantly suppressed (Fig. 3c, d). By using the Foxo1 interference adenovirus AD-siFoxol [12], the decline in Cask mRNA and protein level caused by palmitate treatment could be partly reversed, but there was no change observed in the location of CASK (Fig. 3e-h). These results suggest that
FOXO1 may have indirect and pleiotropic effects in fattyacid-induced islet beta cell damage by modulation of Cask gene transcripts.

But does Foxo1 act alone to suppress the Cask gene or does it require a co-repressor? The siRNAs specific to Ncor (also known as Ncorl, and encoding nuclear receptor co-repressor [NCOR]) and Smrt (also known as Ncor2, and encoding silencing mediator of retinoic acid and thyroid hormone receptor [SMRT]) were designed and synthesised. NCOR and SMRT are the best characterised co-repressors, and are involved in regulatory pathways ranging from genomic stability to metabolic diseases [25]. The data showed that interfering with Smrt consistently increased the expression of Cask, which was not changed after Ncor knockout (Fig. 4c), suggesting that SMRT may be involved in Foxol-mediated suppression of Cask transcription.

Impaired Cask expression mediates fatty-acid-induced insulin secretion defects To further elucidate the mechanism involved in Cask-mediated beta cell dysfunction, five Cask siRNAs and Cask overexpression plasmid pEGFP-N2-Cask were designed and synthesised. Following western blotting verification, two siRNAs and the overexpression plasmid were used in the subsequent experiments (Fig. 5a, b). As expected, the data showed that siCask-1, siCask-5 and palmitate significantly 
Fig. 2 Expression and transcriptional activity of Cask are suppressed by palmitate treatment. INS-1 cells were treated with various concentrations of palmitate or with $0.2 \mathrm{mmol} / \mathrm{l}$ palmitate for different times $(0,12,24$ or $36 \mathrm{~h})$. The expression of Cask was analysed by real-time PCR (a, b) and western blotting $(\mathbf{c}, \mathbf{d})$. The transcriptional activity of Cask promoter was analysed using a luciferase assay $(\mathbf{e}, \mathbf{f})$ and the location of CASK was analysed by immunocytofluorescent staining, the images were recorded at a magnification of $\times 400(\mathbf{g}, \mathbf{h})$. The expression of Cask in $d b / d b$ mice was detected by real-time PCR (i). Values are means $\pm \mathrm{SD}$ and are representative of three individual experiments. ${ }^{*} p<0.05$ and ${ }^{* *} p<0.01$ vs controls
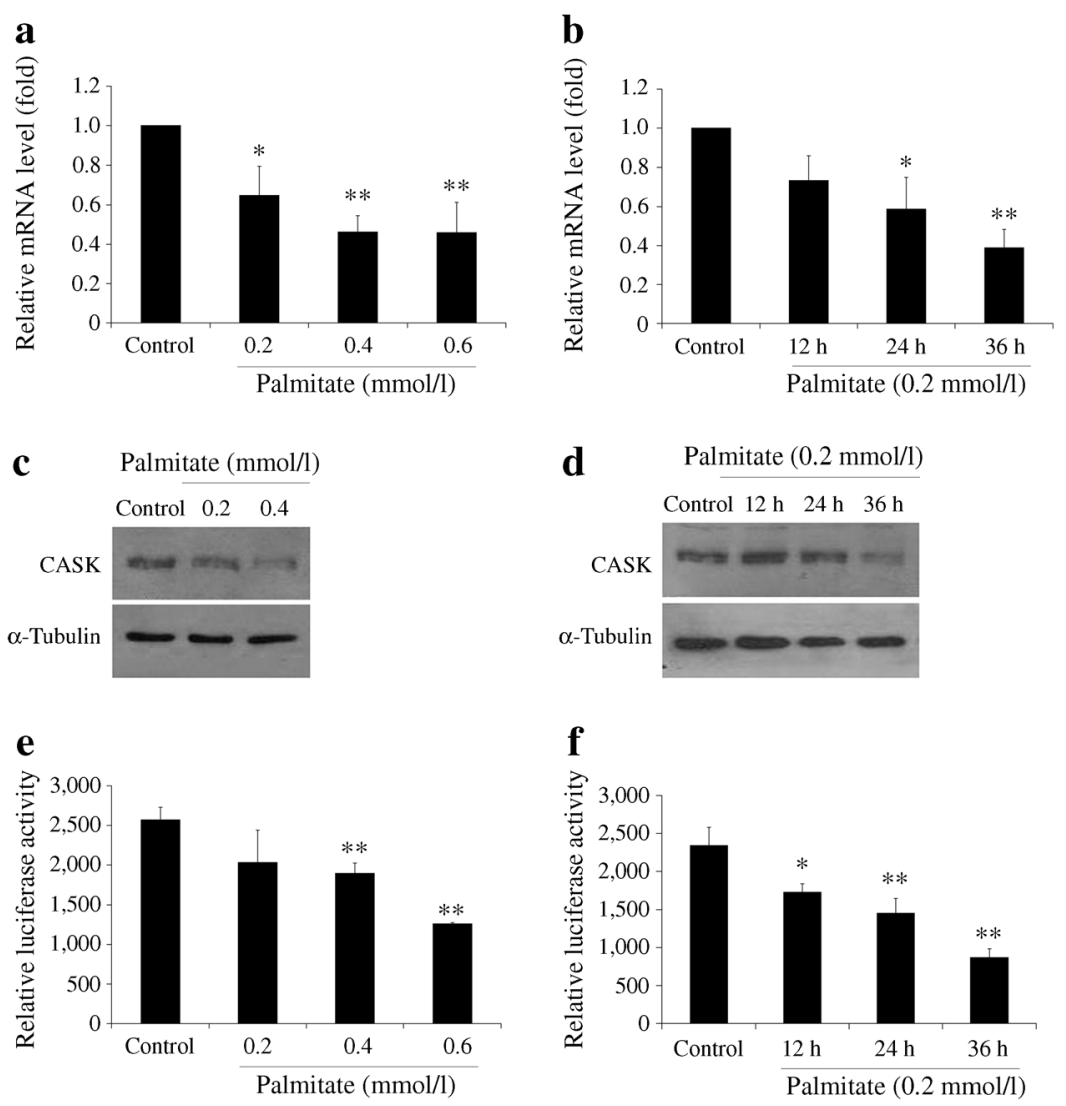

g

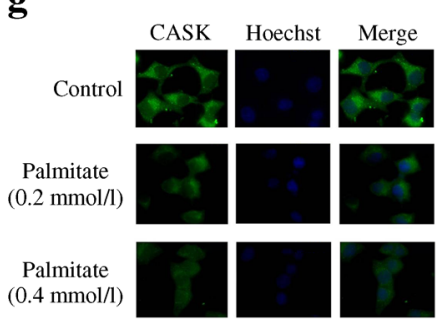

h

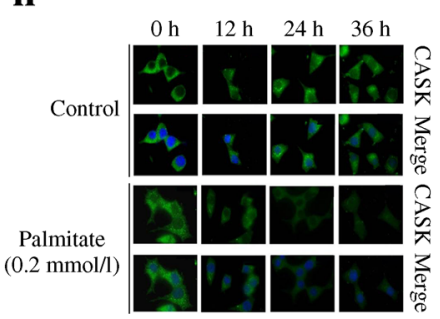

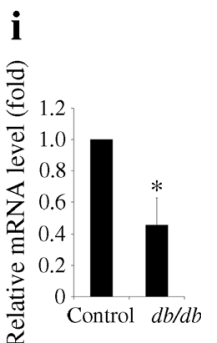

inhibited KSIS in INS-1 cells (Fig. 5c, d); the Cask overexpression plasmid partially reversed this reduction in KSIS (Fig. 5e).

Analysis of the role of CASK in the palmitate-induced insulin secretion dysfunction To assess the role of CASK in the palmitate-induced insulin-secretion dysfunction, INS-1 cells were treated with palmitate, Cask overexpression plasmid or both. The expression of insulin synthesis genes encoding PDX-1, MAFA and neurogenic differentiation factor (NEUROD) was reduced with palmitate treatment, which failed to reverse with the upregulation of Cask expression (Fig. 6a). Furthermore, overexpression of Cask did not alter the inhibition of exocytosis resulting from incubation with the calcium-channel blocker nifedipine (Fig. 6b). In addition, knockdown of CASK attenuated the forskolin-enhanced insulin release that activates the $\mathrm{cAMP} /$ protein kinase A (PKA) pathway (Fig. 6c). However, in INS-1 cells stimulated with high potassium, the fluorescence intensity of CASK in cell membranes was significantly enhanced, indicating that CASK moves from the cytoplasm to the membrane (Fig. 6d).

Knockdown of CASK attenuated the anchoring of insulin granules to cell membranes In vitro, the $\mathrm{SH} 3$ domain of CASK combines with actin-binding protein 4.1, which binds with F-actin, a contractile protein involved in nucleation and aggregation, and links the extracellular matrix with the intracellular cytoskeleton [26, 27]. To determine whether the effect of CASK on insulin secretion was associated with F-actin, we used FITC green fluorescent-labelled CASK and tetramethylrhodamine isothiocyanate (TRITC)-phalloidin fluorescent-labelled F-actin. As shown in Fig. 7a-c, CASK had a low co-localisation with $\mathrm{F}$-actin, and potassium had no effect on the optical distribution and morphology of F-actin, 
Fig. 3 Negative regulation of Cask by FOXO1 with palmitate stimulation. FOXO1 bound directly to the Cask promoter $(-1,842 /-1,580 \mathrm{bp}, 263 \mathrm{bp})$; this binding was enhanced by CAFoxol ADA or $0.2 \mathrm{mmol} / 1$ palmitate in INS-1 cells in a ChIP analysis $(\mathbf{a}, \mathbf{b})$. INS-1 cells were transiently transfected with the indicated concentrations of PCMV5-Foxol for $24 \mathrm{~h}$, the transcriptional activity and protein levels of Cask were detected using luciferase assay and western blotting $(\mathbf{c}, \mathbf{d})$. AdsiFoxo 1 or Ad-control siRNA was transfected into INS-1 cells with or without $0.2 \mathrm{mmol} / \mathrm{l}$ palmitate. Foxol and Cask mRNA levels were detected by real-time PCR (e, f). Cask expression was analysed by western blotting and immunocytofluorescent staining, the magnification of images is $\times 400(\mathbf{g}, \mathbf{h})$. Values are means \pm $\mathrm{SD}$ and are representative of three individual experiments. ${ }^{*} p<0.05$ and $* * p<0.01$ vs controls. Ab, antibody; ADA, CA-Foxol ADA $\mathbf{a}$
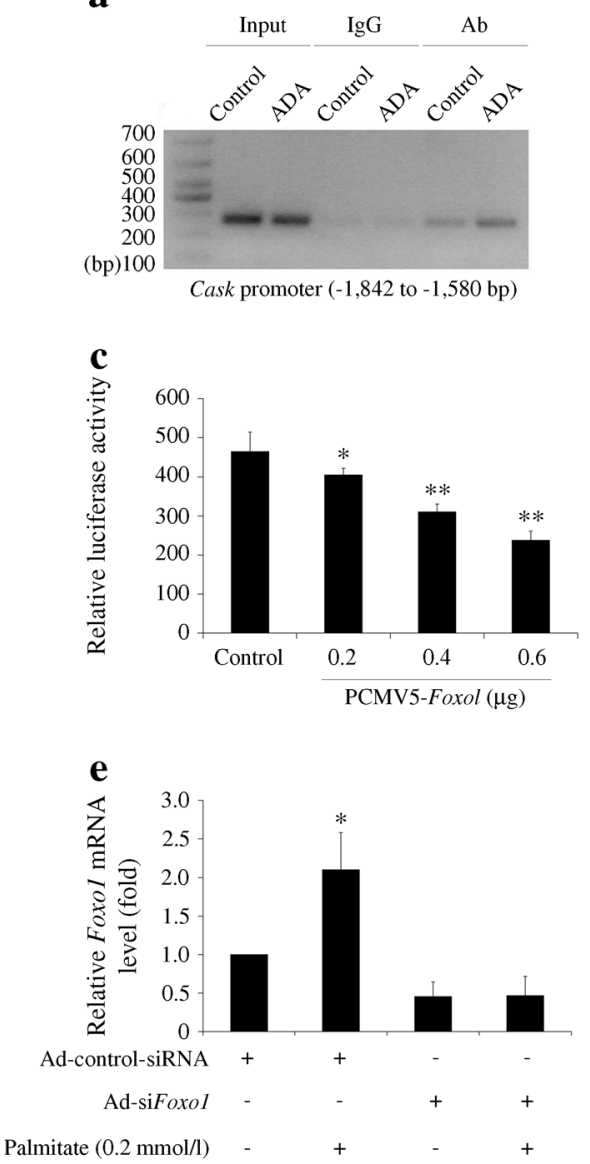

g

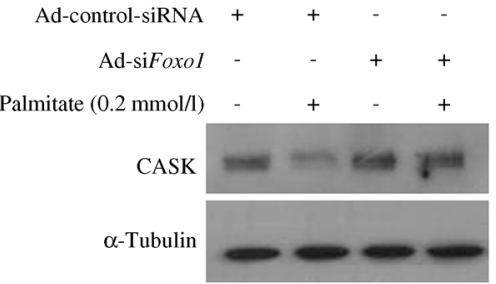

b

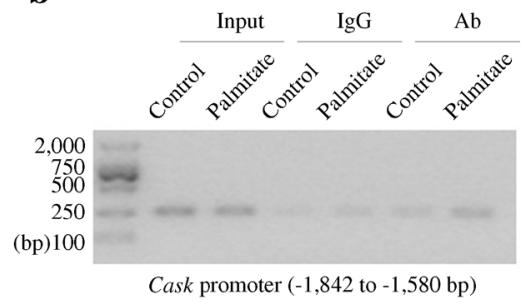

d
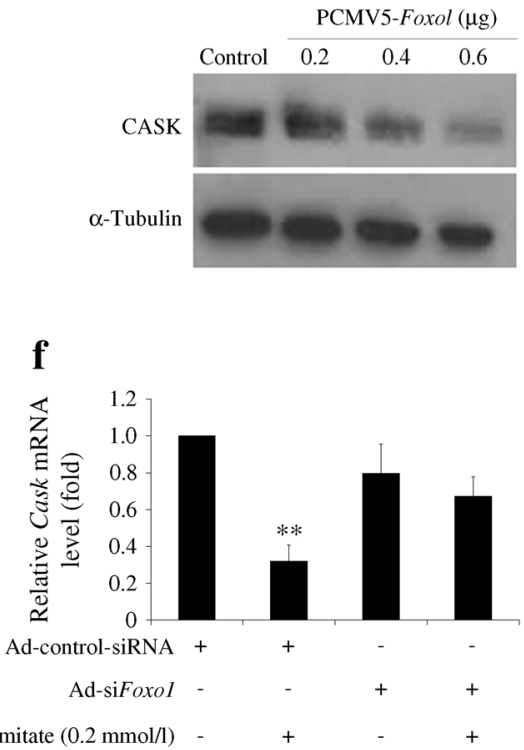

h

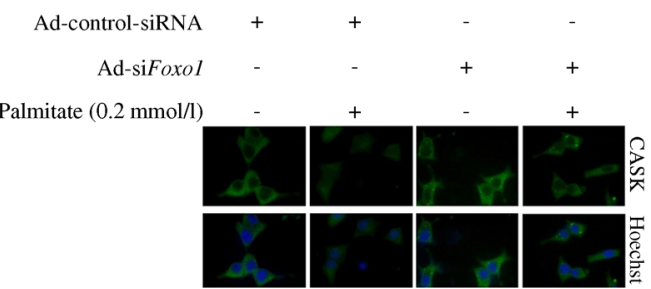

even in cells in which CASK was upregulated or silenced. However, in Cask-silenced cells F-actin filaments exhibited a more decentralised distribution phenotype (Fig. 7c).
Transmission electron microscopy showed no significant changes in the shape, size and total number of vesicles in Cask-silenced cells compared with the controls, yet
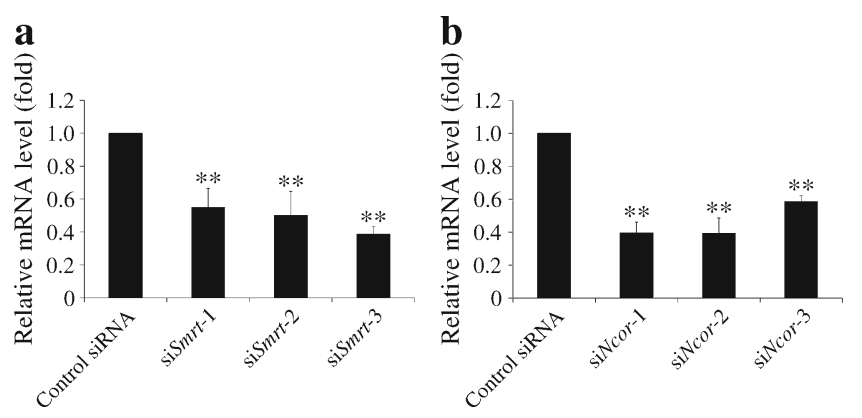

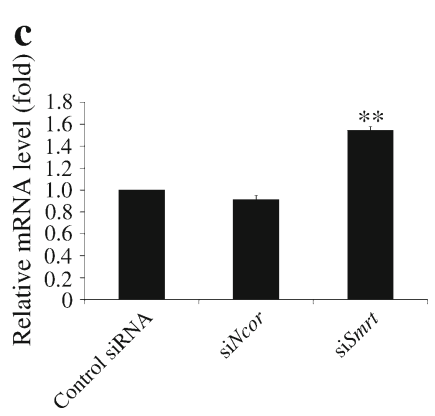

efficiency of interference (a, b) and Cask mRNA levels (c) were measured by real-time PCR. Values are means \pm SD and are representative of three individual experiments. $* * p<0.01$ vs controls
Fig. 4 The co-repressor SMRT is probably involved in Foxol-mediated suppression of Cask transcription. INS-1 cells were transiently transfected with control siRNA, Smrt siRNAs or Ncor siRNAs for $48 \mathrm{~h}$. The 
$\mathbf{a}$
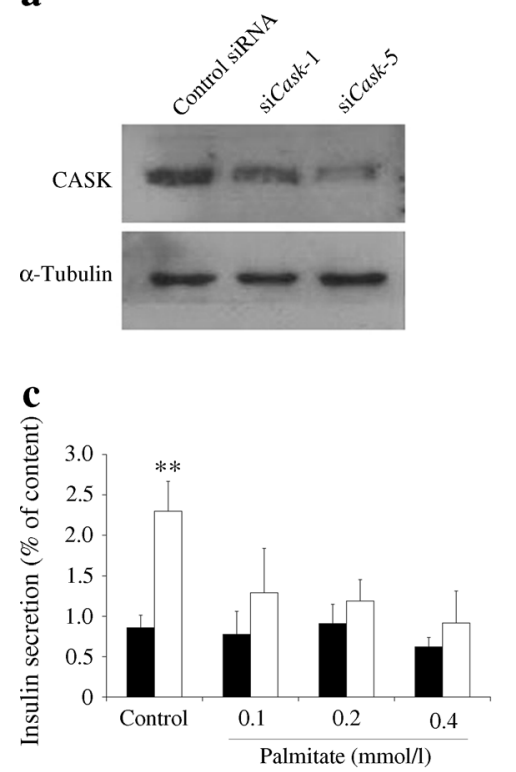

b

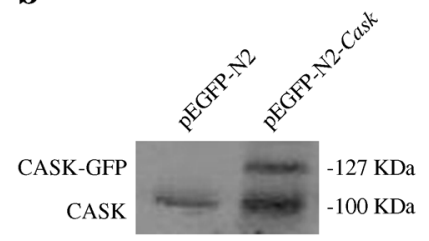

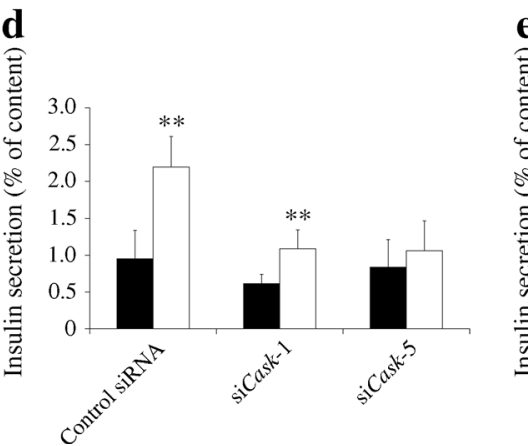

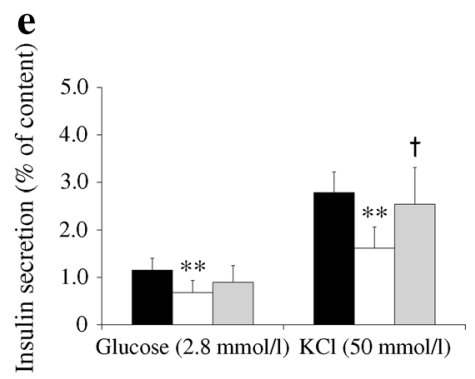

$2.8 \mathrm{mmol} / \mathrm{l}$ glucose; white bars, $50 \mathrm{mmol} / \mathrm{l} \mathrm{KCl})(\mathbf{c}, \mathbf{d})$ and pEGFP-N2, pEGFP-N2-Cask with stimulation of $0.2 \mathrm{mmol} / \mathrm{l}$ palmitate for $48 \mathrm{~h}$ (black bars, control; white bars, palmitate + pEGFP-N2; grey bars, palmitate + pEGFP-N2-Cask) (e). The level of insulin was detected by RIA. Values are means $\pm \mathrm{SD}$ and are representative of three individual experiments. $* * p<0.01$ vs controls; ${ }^{\dagger} p<0.05$ vs control plasmids

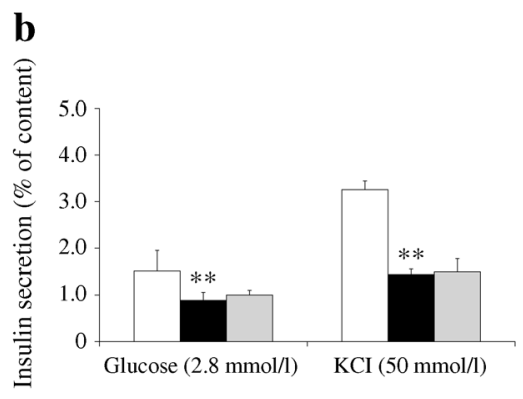

d

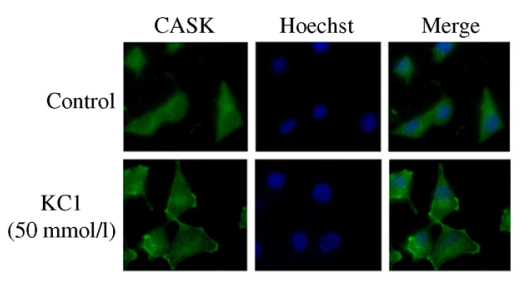

pEGFP-N2-Cask) (b), or transfected with control siRNA and siCask-5 for $48 \mathrm{~h}$, and then stimulated with or without $10 \mu \mathrm{mol} / \mathrm{l}$ forskolin (white bars, control; black bars, siCask-5) (c), respectively. The level of insulin was detected by RIA. INS-1 cells were treated with $50 \mathrm{mmol} / 1 \mathrm{KCl}$ for $2 \mathrm{~min}$. The location of CASK was analysed by immunocytofluorescent staining, the images were recorded at a magnification of $\times 400(\mathbf{d})$. Values are means $\pm \mathrm{SD}$ and are representative of three individual experiments. $*^{* *} p<0.01$ vs controls 


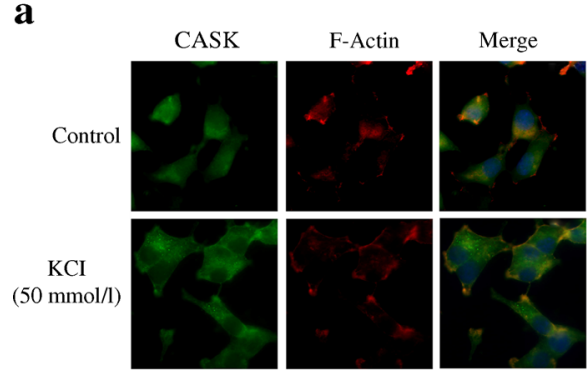

b

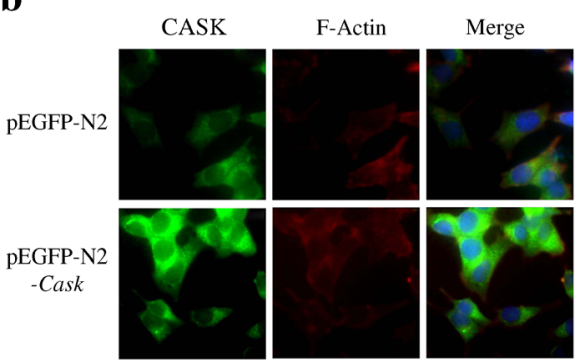

c

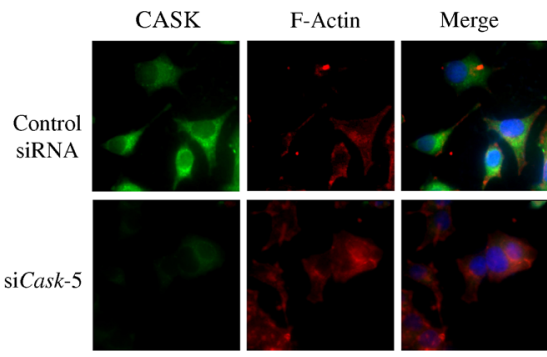

Fig. 7 Knockdown of CASK attenuated insulin granules anchoring to cell membranes. INS-1 cells were treated with $50 \mathrm{mmol} / 1 \mathrm{KCl}$ for $24 \mathrm{~h}$ or were transiently transfected with control plasmids and pEGFP-N2-Cask for $48 \mathrm{~h}$, or control siRNA and siCask-5 for $48 \mathrm{~h}$, respectively (a-c). The locations of CASK and F-actin were analysed by immunocytofluorescent staining. Rat islets were transiently transfected with control siRNA and siCask- 5 for $48 \mathrm{~h}$, then treated with $50 \mathrm{mmol} / 1 \mathrm{KCl}$ for $2 \mathrm{~min}$. Exocytosis of insulin granules was analysed by transmission electron microscopy;

significantly fewer vesicles were observed to be anchored on the cell membranes (Fig. 7d, e). Furthermore, the insulin secretion level was significantly decreased in Cask-silenced rat islets (Fig. 7f).

\section{Discussion}

Our findings demonstrate that FOXO1 mediates pancreatic beta cell dysfunction by downregulating Cask expression, providing a mechanism to link lipotoxicity to type 2 diabetes. This pathway seems to affect the anchoring of insulin granules to the cellular membrane and so reduces exocytosis. The pathogenic effects of FOXO1 may occur when its protein levels are sufficient, after being induced by long-term hyperlipidaemia, to downregulate Cask gene expression. Altering the level d

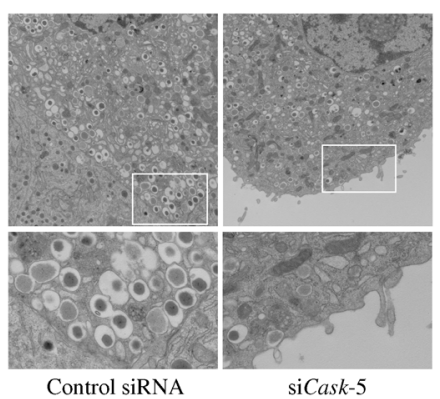

e

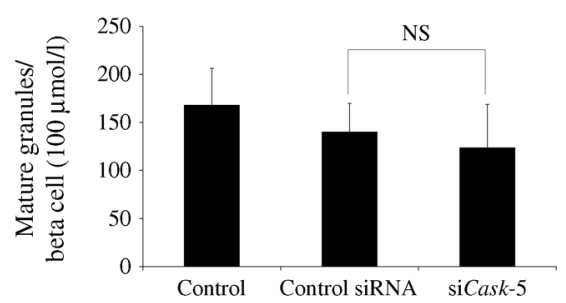

f

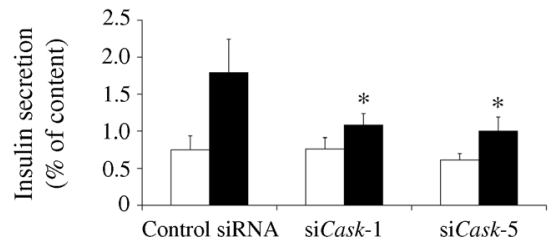

the images were recorded at a magnification of $\times 10,000(\mathbf{d})$ and the total number of insulin granules was determined (e). Rat islets were transiently transfected with control siRNA, siCask-1 and siCask-5 for $48 \mathrm{~h}$ and the level of insulin was detected by RIA (white bars, $2.8 \mathrm{mmol} / 1$ glucose; black bars, $50 \mathrm{mmol} / \mathrm{l} \mathrm{KCl})(\mathbf{f})$. Values are means $\pm \mathrm{SD}$ and are representative of three individual experiments. ${ }^{*} p<0.05$ vs control siRNA. NS, not significant

of CASK protein partly blocks this pathogenic effect, which suggests a major role for CASK in the mediation of FOXO1 effects.

Pancreatic beta cell dysfunction can be characterised as a defect of insulin synthesis and/or secretion. Studies have indicated that abnormal regulation of the insulin synthesis pathway and lipotoxicity generated by diet or NEFA $[28,29]$ could contribute to type 2 diabetes individually or in combination. However, the modulatory mechanisms are still incompletely understood. FOXO1 is a key molecule involved in beta cell stress response, proliferation and apoptosis [10, 30]; we had previously identified Cask as a downstream FOXO1 target gene [12]. CASK protein interacts with its target proteins through its PDZ domain, $\mathrm{SH} 3$ domain, the C-terminal region or the CaMK domain, and participates in the construction of the cytoskeleton and cell junctions; it is involved in signal transduction, the regulation of gene expression, the release 
of neurotransmitters and the development of neurons [15, 31]. The similarities of the insulin exocytotic compound and the release assembly of neurotransmitters [17, 32, 33], and the abundant expression of Cask in isolated islets and pancreatic beta cell lines [16], made the interactions between FOXO1 and Cask worth investigating. In this study, the expression and the transcriptional activity of Cask were downregulated by palmitate. Also Cask silencing suppressed insulin secretion in INS- 1 cells and primary islets, suggesting that CASK may be involved in insulin secretion by pancreatic beta cells. Furthermore, we demonstrated that FOXO1 could bind to the Cask gene promoter. The binding was enhanced by palmitate, confirming that FOXO1 has a negative regulatory effect on Cask. Moreover, interfering with Smrt increased the expression of Cask, suggesting that SMRT probably acts as a corepressor for Cask with FOXO1, a potential relationship that needs further investigation. Nevertheless, Cask overexpression could partially reverse the reduction of KSIS induced by palmitate. These findings open up the possibility that a single transcriptional factor might provide a pathway that allows cellular cytoskeletal proteins to fine tune beta cell insulin release. Thus, FOXO1 may have a critical role in beta cell function.

The exact mechanism underlying the role of CASK in insulin synthesis and the transportation, anchoring and secretion of insulin granules then becomes a key question. In the current study, the expression of three critical insulin synthesis genes encoding MAFA, NEUROD and PDX-1 [34] were downregulated with palmitate treatment. That the downregulation was not reversed by overexpression of Cask indicates that multiple biological processes were modulated, excluding the association of CASK protein. This was in accordance with the phenotype that loss of Cask affected insulin secretion in just $1 \mathrm{~h}$ of KSIS.

We then focused on the preparation of the secretory phase of insulin (i.e. the transportation, anchoring and exocytosis of insulin granules). Here, we established a connection between CASK and the exocytosis of insulin granules. We examined the effect of treatment with an adenylate cyclase agonist (forskolin) and a calcium-channel blocker (nifedipine) on the regulation of Cask levels. Forskolin activates the cAMP/PKA pathway to significantly increase membrane depolarisation and induce insulin secretion [35], while nifedipine could inhibit insulin secretion triggered by intracellular calcium. In this study, the findings that the promotion of insulin release with forskolin was suppressed by Cask gene silencing and that the inhibition of insulin secretion with nifedipine was not affected by Cask overexpression indicate that Cask is potentially responsible for insulin secretion in the exocytotic process of the granules. Its role was confirmed by the finding that silencing Cask led to deficiencies in both basal and stimulated insulin secretion. Moreover, our results demonstrated that, with high potassium stimulation, CASK moves from the cytoplasm to the plasma membrane, and hinted that CASK is involved downstream of the insulin-secretion pathway. Optically, CASK did not change between intranuclear and extranuclear locations. Although the significant reduction in Cask expression and increase in Foxol were confirmed in $d b / d b$ miceresults from INS-1 cells require caution when being interpreted in a wider context - we attempted to validate our results in other pancreatic cell lines and Cask conditional knockout mice.

F-actin, a cytoskeleton protein, prevents the anchoring and fusion of insulin vesicles in the plasma membrane [26, 27]. It can combine with CASK-SH3 through protein 4.1 in the haemocyte [24]. Therefore, the indirect combination of CASK and $\mathrm{F}$-actin in cell membranes might regulate insulin secretion and have a potential role in palmitate-induced beta cell dysfunction. In our studies, CASK appeared to induce the local assembly of F-actin, resulting in a more localised distribution of F-actin. In addition, CASK seemed to reduce the obstructing effect of F-actin on the anchoring and fusion of granules during exocytosis. Using electron microscopy, we showed that knockdown of CASK blocked the anchoring of insulin granules in islets, suggesting that FOXO1 plays a central role in translating environmental lipotoxic stress from NEFA to the genomic regulation of beta cell function. This regulation might be effected via a modulation of Cask expression, affecting the ability of CASK to combine with other secretion-related cytoskeletal proteins to obstruct the exocytosis of insulin granules.

In conclusion, our study reveals that FOXO1 expression is inducible by some pathogenic factors of diabetes, and overexpression leads to beta cell failure. Importantly, our results link overnutrition and reduction in Cask gene expression to the pathological effects in type 2 diabetes through the elevation of FOXO1. This study broadens our understanding of the pathophysiological development of diabetes and describes a novel regulatory pathway involving transcriptional factors as intermediaries between environmental stress and disease phenotypes.

Acknowledgements The authors gratefully acknowledge the generous support of the Collaborative Innovation Center for Cardiovascular Disease Translational Medicine of Jiangsu Province.

Funding This work was supported by grants from: (1) the Key Program of National Natural Science of China (81130013) to XH; (2) the Special Funds for Major State Basic Research Program of China (973 Program, 2012CB524900) to XH; (3) the Natural Science Foundation of Jiangsu Province (BK2012752) to YW; and (4) the National Natural Science Foundation of China (81370878) to HL.

Duality of interest All authors declare that there is no duality of interest associated with this manuscript.

Contribution statement All authors took part in the conception and design of the study, as well as either drafting or critically revising the 
manuscript. All authors have approved the final version of the manuscript. NH, ZZ, DW, YL and HC collected the data and carried out the data analysis. $\mathrm{XH}$ is responsible for the integrity of the work as a whole.

\section{References}

1. Brownlee M (2005) The pathobiology of diabetic complications: a unifying mechanism. Diabetes 54:1615-1625

2. Donath MY, Storling J, Maedler K, Mandrup-Poulsen T (2003) Inflammatory mediators and islet beta-cell failure: a link between type 1 and type 2 diabetes. J Mol Med (Berl) 81:455-470

3. Weir GC, Laybutt DR, Kaneto H, Bonner-Weir S, Sharma A (2001) Beta-cell adaptation and decompensation during the progression of diabetes. Diabetes 50(Suppl 1):S154-S159

4. Seidell JC (2000) Obesity, insulin resistance and diabetes - a worldwide epidemic. Br J Nutr 83(Suppl 1):S5-S8

5. Zimmet P, Alberti KG, Shaw J (2001) Global and societal implications of the diabetes epidemic. Nature 414:782-787

6. Kahn BB, Flier JS (2000) Obesity and insulin resistance. J Clin Invest 106:473-481

7. Weyer C, Foley JE, Bogardus C, Tataranni PA, Pratley RE (2000) Enlarged subcutaneous abdominal adipocyte size, but not obesity itself, predicts type II diabetes independent of insulin resistance. Diabetologia 43:1498-1506

8. Saltiel AR (2001) New perspectives into the molecular pathogenesis and treatment of type 2 diabetes. Cell 104:517-529

9. Tang ED, Nunez G, Barr FG, Guan KL (1999) Negative regulation of the forkhead transcription factor FKHR by Akt. J Biol Chem 274:16741-16746

10. Martinez SC, Tanabe K, Cras-Meneur C, Abumrad NA, BernalMizrachi E, Permutt MA (2008) Inhibition of Foxol protects pancreatic islet beta-cells against fatty acid and endoplasmic reticulum stress-induced apoptosis. Diabetes 57:846-859

11. Glauser DA, Schlegel W (2007) The emerging role of FOXO transcription factors in pancreatic beta cells. J Endocrinol 193:195-207

12. Lin HY, Yin Y, Zhang JX et al (2012) Identification of direct forkhead box $\mathrm{O} 1$ targets involved in palmitate-induced apoptosis in clonal insulin-secreting cells using chromatin immunoprecipitation coupled to DNA selection and ligation. Diabetologia 55:2703-2712

13. Slawson JB, Kuklin EA, Ejima A, Mukherjee K, Ostrovsky L, Griffith LC (2011) Central regulation of locomotor behavior of Drosophila melanogaster depends on a CASK isoform containing CaMK-like and L27 domains. Genetics 187:171-184

14. Najm J, Horn D, Wimplinger I et al (2008) Mutations of CASK cause an X-linked brain malformation phenotype with microcephaly and hypoplasia of the brainstem and cerebellum. Nat Genet 40:1065-1067

15. Chung WC, Huang TN, Hsueh YP (2011) Targeted deletion of CASK-interacting nucleosome assembly protein causes higher locomotor and exploratory activities. Neurosignals 19:128-141

16. Suckow AT, Comoletti D, Waldrop MA et al (2008) Expression of neurexin, neuroligin, and their cytoplasmic binding partners in the pancreatic beta-cells and the involvement of neuroligin in insulin secretion. Endocrinology 149:6006-6017

17. Hori Y, Gu X, Xie X, Kim SK (2005) Differentiation of insulinproducing cells from human neural progenitor cells. PLoS Med 2:e103
18. Han X, Sun Y, Scott S, Bleich D (2001) Tissue inhibitor of metalloproteinase-1 prevents cytokine-mediated dysfunction and cytotoxicity in pancreatic islets and beta-cells. Diabetes 50:1047-1055

19. Wrede CE, Dickson LM, Lingohr MK, Briaud I, Rhodes CJ (2002) Protein kinase B/Akt prevents fatty acid-induced apoptosis in pancreatic beta-cells (INS-1). J Biol Chem 277:49676-49684

20. Zhu ZQ, Wang D, Xiang D, Yuan YX, Wang Y (2014) Calcium/ calmodulin-dependent serine protein kinase is involved in exendin4-induced insulin secretion in INS-1 cells. Metabolism 63:120-126

21. Meng Z, Lv J, Luo Y et al (2009) Forkhead box O1/pancreatic and duodenal homeobox 1 intracellular translocation is regulated by c-Jun $\mathrm{N}$-terminal kinase and involved in prostaglandin E2-induced pancreatic beta-cell dysfunction. Endocrinology 150:5284-5293

22. Zhang X, Yong W, Lv J et al (2009) Inhibition of forkhead box O1 protects pancreatic beta-cells against dexamethasone-induced dysfunction. Endocrinology 150:4065-4073

23. Zhang HJ, Walseth TF, Robertson RP (1989) Insulin secretion and cAMP metabolism in HIT cells. Reciprocal and serial passagedependent relationships. Diabetes 38:44-48

24. Kharroubi I, Ladriere L, Cardozo AK, Dogusan Z, Cnop M, Eizirik DL (2004) Free fatty acids and cytokines induce pancreatic beta-cell apoptosis by different mechanisms: role of nuclear factor-kappaB and endoplasmic reticulum stress. Endocrinology 145:5087-5096

25. Mottis A, Mouchiroud L, Auwerx J (2013) Emerging roles of the corepressors NCoR1 and SMRT in homeostasis. Genes Dev 27:819-835

26. Newsholme P, Brennan L, Rubi B, Maechler P (2005) New insights into amino acid metabolism, beta-cell function and diabetes. Clin Sci (Lond) 108:185-194

27. Li G, Rungger-Brandle E, Just I, Jonas JC, Aktories K, Wollheim CB (1994) Effect of disruption of actin filaments by Clostridium botulinum $\mathrm{C} 2$ toxin on insulin secretion in HIT-T15 cells and pancreatic islets. Mol Biol Cell 5:1199-1213

28. He TT, Cao XP, Chen RZ et al (2011) Down-regulation of peroxisome proliferator-activated receptor gamma coactivator1alpha expression in fatty acid-induced pancreatic beta-cell apoptosis involves nuclear factor-kappaB pathway. Chin Med J (Engl) 124:3657-3663

29. Tuo Y, Wang D, Li S, Chen C (2011) Long-term exposure of INS-1 rat insulinoma cells to linoleic acid and glucose in vitro affects cell viability and function through mitochondrial-mediated pathways. Endocrine 39:128-138

30. Kitamura T (2013) The role of FOXO1 in $\beta$-cell failure and type 2 diabetes mellitus. Nat Rev Endocrinol 9:615-623

31. Hsueh YP (2006) The role of the MAGUK protein CASK in neural development and synaptic function. Curr Med Chem 13:1915-1927

32. Rulifson EJ, Kim SK, Nusse R (2002) Ablation of insulin-producing neurons in flies: growth and diabetic phenotypes. Science 296: $1118-1120$

33. Kozlova EN, Jansson L (2009) Differentiation and migration of neural crest stem cells are stimulated by pancreatic islets. Neuroreport 20 : 833-838

34. Andrali SS, Sampley ML, Vanderford NL, Ozcan S (2008) Glucose regulation of insulin gene expression in pancreatic beta-cells. Biochem J 415:1-10

35. Li J, Luo R, Kowluru A, Li G (2004) Novel regulation by Rac1 of glucose- and forskolin-induced insulin secretion in INS-1 beta-cells. Am J Physiol Endocrinol Metab 286:E818-E827 